\title{
Neurofibromatosis Type-1 and Hypothyroidism
}

\author{
Prateek Kumar Panda ${ }^{1} \cdot$ Indar Kumar Sharawat ${ }^{1}$
}

Received: 18 March 2020 / Accepted: 30 March 2020/Published online: 17 April 2020

(C) Dr. K C Chaudhuri Foundation 2020

To the Editor: A 5-y-old boy presented with complaints of multiple gradually increasing painless soft tissue swellings over trunk and extremities for the last one year. The parents also complained that the child is not attaining height as per peers. On examination, the child had multiple Cafe-au-Lait spots, dermal and subcutaneous neurofibromas, Lisch nodules in the bilateral iris, and short stature (height for age $<-3 \mathrm{SD}$ ), with upper and lower segment ratio of 1.2. The examination of the parents was non-contributory. Investigation showed delayed bone age ( $3 \mathrm{y})$ and abnormal thyroid profile (FT3$0.46 \mathrm{ng} / \mathrm{ml}$, FT4- $2.7 \mu \mathrm{g} / \mathrm{ml}$, TSH- $26.34 \mathrm{uIU} / \mathrm{ml}$, anti-TPO antibody-negative). Magnetic resonance imaging of the brain revealed non-specific signal changes in the periventricular white matter. A diagnosis of neurofibromatosis type- 1 with hypothyroidism was concluded. He was started on oral thyroxin and showed improvement in height velocity at six months follow up.

The co-existence of hypothyroidism in children with neurofibromatosis type-1 (NF1) has only been described in a few anecdotal case reports in existing literature $[1,2]$. Only one study to date has systematically evaluated thyroid abnormalities in children with NF1 and did not find an increased incidence as compared to the normal population [3]. Few case reports of concomitant occurrence of various autoimmune thyroid diseases like Hashimoto's thyroiditis and Graves' disease, as well as thyroid neuroendocrine tumors and other thyroid neoplasms like C-cell hyperplasia, medullary and papillary thyroid carcinoma, have been reported in adults with NF1 [4, 5].

Neurofibromin is a GTPase-activating protein that downregulates p21-ras proto-oncogene. The loss of function of neurofibromin in NF1 patients leads to uncontrolled cell growth and increased tumor formation [3]. Reduced

Indar Kumar Sharawat

sherawatdrindar@gmail.com

1 Pediatric Neurology Division, Department of Pediatrics, All India Institute of Medical Sciences, Rishikesh, Uttarakhand 249203, India neurofibromin production leads to decreased Fas ligand expression, which subsequently prevents apoptosis of CD4+ T cells. Most of the previous authors proposed this as the most plausible mechanism behind the development of autoimmune thyroid disease in children with NF1, as these CD4+ T cells play an important role in the development of autoimmunity. Our case has a unique presentation in the sense that he developed hypothyroidism in the absence of any evidence of autoimmunity and had the youngest age of presentation at five years, compared to all published cases [3]. Moreover, at least 13-23\% of children with NF1 have short stature and the growth velocity significantly improved with thyroid hormone replacement in our case, thereby indicating a need for screening for hypothyroidism in NF1 children with short stature.

\section{Compliance with Ethical Standards}

Conflict of Interest None.

\section{References}

1. Sasazawa DT, Tsukumo DM, Lalli CA. Myxedema coma in a patient with type 1 neurofibromatosis: rare association. Arq Bras Endocrinol Metabol. 2013;57:743-7.

2. Sakane N, Shirakata S, Jin M-B, Torii T, von Yoshida T. Recklinghausen's disease with hyperthyroidism. Intern Med. 1997;36:938.

3. Güler S, Yeșil G, Önal H. Endocrinological evaluations of a neurofibromatosis type 1 cohort: is it necessary to evaluate autoimmune thyroiditis in neurofibromatosis type 1? Balkan Med J. 2017;34:5226.

4. Yalcin B, Yalcçin B, Tamer E, Gür, et al. Neurofibromatosis 1/ Noonan syndrome associated with Hashimoto's thyroiditis and vitiligo. Acta Derm Venereol. 2006;86:80-1.

5. Nabi J. Neurofibromatosis type 1 associated with Hashimoto's thyroiditis: coincidence or possible link. Case Rep Neurol Med. 2013;2013:910656.

Publisher's Note Springer Nature remains neutral with regard to jurisdictional claims in published maps and institutional affiliations. 